\title{
A Benefit-Cost Analysis of Food and Biodegradable Waste Treatment Alternatives: The Case of Oita City, Japan
}

\author{
Micky A. Babalola \\ Graduate School of Education, Hiroshima University, 1-1-1 Kagamiyama, Higashi-Hiroshima, \\ Hiroshima 739 8524, Japan; mickba15@hiroshima-u.ac.jp
}

Received: 27 January 2020; Accepted: 23 February 2020; Published: 3 March 2020

\begin{abstract}
As the generation of food scrap, kitchen, and biodegradable wastes increases, the proper handling of these wastes is becoming an increasingly significant concern for most cities in Japan. A substantial fraction of food and biodegradable waste (FBW) ends up in the incinerator. Therefore, an analytic hierarchy process (AHP) benefit-cost analysis technique was employed in this study to compare different FBW treatment technologies and select the most appropriate FBW disposal technology for Oita City. The four FBW treatment options considered were those recommended by the Japanese Food Waste Recycling Law: anaerobic digestion, compost, landfill, and incineration, which is currently in use. The fundamental AHP was separated into two hierarchy structures for benefit analysis and cost analysis. The criteria used in these two analyses were value added, safety, efficiency, and social benefits for benefit analysis, and cost of energy, cost of operation and maintenance, environmental constraints, and disamenity for cost analysis. The results showed that anaerobic digestion had the highest overall benefit while composting had the least cost overall. The benefit-cost ratio result showed that anaerobic digestion is the most suitable treatment alternative, followed by composting and incineration, with landfill being the least favored. The study recommends that composting could be combined with anaerobic digestion as an optimal FBW management option in Oita City.
\end{abstract}

Keywords: criteria; food and biodegradable waste; analytic hierarchy process; benefit-cost analysis; multi-criteria decision analysis; waste disposal technology; anaerobic digestion

\section{Introduction}

In the discourse of developing, analyzing, implementing, and optimizing frameworks for existing waste management systems in any city, the 2030 Agenda for Sustainable Development comes to mind. This agenda comprises 17 Sustainable Development Goals (SDGs) and 169 targets set as the defined requirements for achieving sustainable development by 2030, and a strategy for accomplishing sustainability [1]. Urban development and management in general brings many challenges to light. Cities can play an essential role in this regard by making human settlements habitable, sustainable, safe, and resilient (SDG 11), as well as by ensuring sustainable consumption and production patterns (SDG 12) in achieving the SDGs.

The considerable amounts of food scraps and decomposable waste generated within cities in Japan have resulted in controversial issues of substantial concern. The creation and effective management of these organic wastes are too much for the municipal and local authorities to be able to properly manage. These authorities are wrestling with substantial amounts of food and biodegradable waste (FBW), waste administration costs, and methods of treatment, as well as the potential impact of generated waste on the local environment [2]. Furthermore, issues such as funding and searching for the most 
suitable dumping equipment, wrongful disposal, conflicts concerning various areas across long hauls of waste, and concerns regarding unwanted disposal outcomes remain challenging [3,4].

Currently, there is an increasing demand for the proper integration of effective policies that aim at practicing sustainable waste management in the main waste stream [5-7]. To this end, the Japanese government legislated the Act on the Promotion of the Recycling of Recyclable Food Resources, titled the Food Recycling Act (the Sound Material-Cycle Society in the act mentions the Biomass Nippon Strategy) in 2001 and reviewed it in 2015 [5,6,8]. This act was enacted to champion the recycling of recyclable organic resources, primarily as feedstock for ethanolization and bio-gasification technologies [8]. Also included are waste preventative policies intended to reduce, reuse, and recycle the quantity of FBW collected by local authorities from households. Oita Prefecture is currently implementing these policies alongside the Oita Zero-Waste Strategy [9].

Oita is the capital of Oita Prefecture, with a projected populace of 479,466 people and 218,532 homes (as of 30 January 2018), and a density of 954.35 residents $/ \mathrm{km}^{2}$ [10,11]. The volume and handling methods of FBW and the inhabitants of Oita City are some of the reasons that this city was chosen for this research. In addition, this city is used as a reference point for the surrounding cities with similar conditions. At present, a total $21,976 \mathrm{t}$ of food and kitchen waste is created monthly (38.6\% of the total MSW), and almost $65 \%$ of the inhabitants are middle-income households $[9,10]$. FBW is sent directly to combustion, primarily managed by two incineration plants [11,12].

Despite the sound support in favor of material recycling and recovery, reinforced by legislation, incineration continues to serve as the chief and the predominant source of MSW in most cities in Japan [7,11-13]. FBW exerts a straightforward and substantial impact on the volume and structure of MSW, and constitutes the most sizable share mix with a low calorific value and high water content [14]. However, energy and combustion efficiency decrease whenever these wastes are incinerated [7,15-17].

Current findings have shown the incineration of FBW has raised concerns in terms of economic and ecological consequences (regarding the generation of greenhouse gases (GHG)) [18-20]. The investigation of food waste management systems by Bernstad and la Cour Jansen [16] highlighted that whenever support fuel (e.g., diesel) is used, it eliminates the encouragement aimed at material recycling as a result of insufficient thermal capacity in damp FBW. In addition, it hinders the use of other waste materials (plastics and paper), when they are utilized to increase the calorific capacity of composting [16]. Villanueva and Wenzel [21] argued that recycling of material is more profitable than incineration in terms of energy utilization and energy-related impacts. Following a comprehensive assessment of various recycling techniques used within Japan, Takata et al. [5] established that the cost and GHG emissions of FBW treatment equipment are below those of incineration facilities. Put differently, considerable attention should be focused on the specific type of waste treatment technology used and its potential impacts on the environment [22-24].

A full-scale investigation is required, because of the complexities of FBW management, to select the right FBW disposal method. Choosing the appropriate waste handling method will be helpful in mitigating negative ecological consequences, and will simultaneously save money and time. For this purpose, this study assessed the suitability of FBW treatment technology in Oita City, employing an analytic hierarchy process (AHP) benefit-cost analytical approach. The focus was on the FBW treatment methods endorsed in the Food Recycling Act, which include incineration with heat and electric energy recovery; landfill, which lacks any kind of energy retrieval; composting; and anaerobic digestion $[7,8,25]$.

This study was based on the theoretical improvement and application of an incorporated food and biodegradable waste management system (FBWMS) to facilitate the ability to address cultural, economic, environmental, political, social, and technological concerns in sustainable waste management systems. The present FBWMS practices and the possibility of enhancing this current system through applying multi-criterion decision analysis (MCDA) were the core of this study. Therefore, the specific objectives of this study were to examine which waste treatment alternatives would be the least costly and the most beneficial options to treat the amount of FBW generated. Consequently, investigating the 
potential benefit and cost of FBW treatment facilities using Oita City as a case study will contribute to the value increase of incorporating FBW management within the framework of decision support (making) in the MSW administration system [2]. Recently, the application of MCDA techniques in tackling waste management challenges has been increasing. For this purpose, this study provides additional knowledge by demonstrating how an AHP benefit-cost analysis can be employed to settle waste management challenges.

\section{The Application of Multi-Criteria Decision Analysis (MCDA)}

AHP has been conceivably the most often applied MCDA technique in constructing and solving complex decisions by key decision-makers [26-33]. According to Belton and Steward [34], MCDA is an umbrella phrase utilized to characterize a compilation of established procedures that aims at examining the specific explanation of multiple criteria in supporting of both single and group decision-makers to execute informed decisions. In support of this, Babaloa [2] described MCDA as a functional apparatus for environmental evaluation wherein a complicated, interconnected, and wide range of ecological, socio-cultural, technical, economic, and monetary concerns are considered. In addition, where required tradeoffs between competing goals and standards are equally measured. MCDA provides a significant and straightforward decision-making framework that are primarily relevant to circumstances where a single criterion disappoints, and substantial environmental and societal consequences are impossible to monetized $[35,36]$.

The flexible nature of MCDA makes it applicable at all stages of decision-making, from the consideration of project options to wider-rang of policy decisions [26,27]. The strong point of MCDA lies in the significant assessments of criteria that are not in monetary terms. On the contrary, they are regularly adjusted by means of weighing, scoring, and ranking with a more diverse spectrum of qualitative influences. [2,34,37]. For instance, various ecological and societal standards, maybe established in combination with monetary benefits and costs. Similarly, both financial and non-monetary goals may well affect policy decisions $[2,34,37]$. MCDA can be adapted to use judgements ideally aimed at problems with non-monetize criteria. Most often, it offers the possibility of an additional representation of tradeoffs to be made in the decision problem. Therefore, pairwise comparison is a predominantly used interactive approach to establish tradeoff relationships among key criteria [29,30].

This technique is considered for both qualitative and quantifiable terms during a realistic decision-making environment. It is beneficial in situations where decision-makers are confronted with difficulties when handling qualitative information $[35,36,38]$. The implementation of MCDA procedures to waste treatment challenges, in general, comprises the combination of cultural, economic, ecological, political, and societal principles in conjunction with the priorities of stakeholders while upsetting the difficulties in monetizing basically nonmonetary components [27,28,36,39-43]. A significant majority of these articles elaborate reasonable decision-making regarding waste management regulations through the examination of an extensive variety of potential impacts. These impacts are frequently not considered in economic analyses due to the lack of measurement in terms of monetary value [36].

The real-life applications of AHP techniques have been shown beyond doubt to be valuable decision-making tools. These applications have been grouped by Vaidya and Kumar [32] into the fields of choice, assessment, planning and development, allocations, priority and ranking, decision making, and benefit-cost analysis. Furthermore, Williams [44] proceeded to substantiate that the straightforwardness and the flexibility of AHP have naturally made it more universally applicable; as such, it is implemented in military, manufacturing, management, education, government, society, sports, personnel, engineering, and policymaking [32,45]. Consequently, this study employs the AHP based benefit-cost analysis to evaluate the optimum disposal technology for FBWM in Oita City, Japan. The illustrations of this technique have been presented by Anagnostopoulos [33], Ishizaka and Labib [45], Beria et al., [46], Wedley et al. [47], and Wedley et al [48].

The rationale for applying AHP based benefit-cost analysis in this study is based on its straightforwardness, familiarity, and flexibility. Most interesting is the merit of AHP in contrast 
to and in connection with other techniques of MCDA [31,45]. Apart from the merits of AHP, one of the shortcomings of the subjective nature of the process where decision makers cannot absolutely guarantee not mixing their decisions with personal opinions, feelings, and biases is of concern. In addition, more resources and time are needed when dealing with a large number of hierarchy levels in a complex decision-making process. As such, the number of pairwise comparisons depends on the hierarchy levels. Nonetheless, Huang et al. [49] emphasized that, regardless of what techniques of MCDA are applied, the choice is primarily subjected to the priority of the decision-maker. For this purpose, the practical implementation of this technique will be outlined in this study with the goal to assess the optimum disposal technology for FBWM in Oita City, Japan.

Regardless, AHP is suitable for measuring non-material criteria and assessing decisions in a multi-tiered hierarchy of goals regarding criteria, sub-criteria, and alternatives. The AHP benefit-cost approach primarily includes two hierarchies for the same set of objective or goal, one for benefit and the other for cost analysis $[31,47,48]$. Through pairwise comparisons of a set of criteria, the weights and composite priorities of the options are obtained for both the benefit and cost analyses. [47,48]. The resulting composting benefits and costs priorities are then compared to select the alternative with the highest ratio. In the case where the comparisons are inconsistent, Saaty offers a procedure for enhancing consistency [29-31]. The step-by-step analytical process in AHP proposed by Saaty \& Vargas [31] is shown in Figure 1.

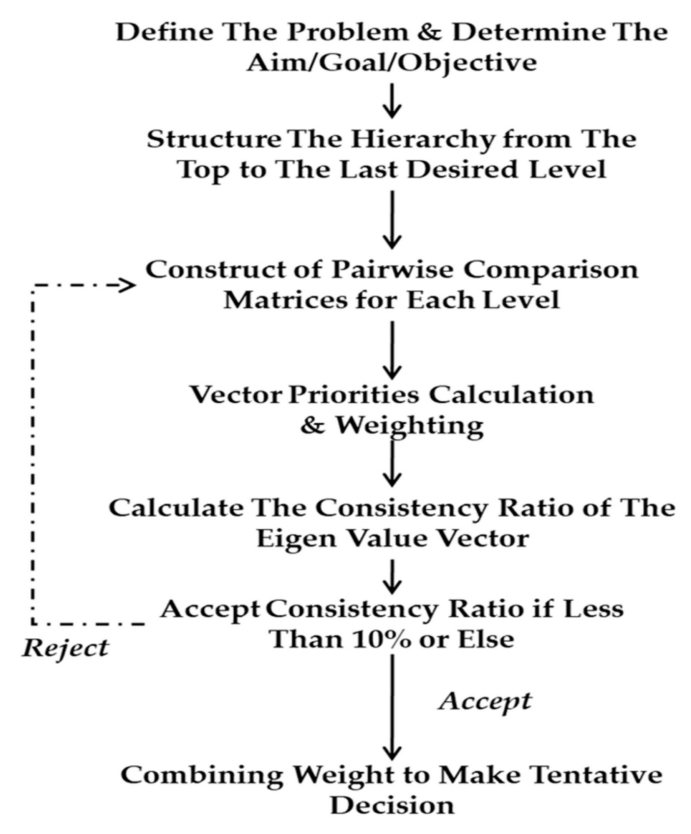

Figure 1. The Step-by-step analytical hierarchy process.

\section{Materials and Methods}

The AHP is founded on a distinct mathematical arrangement of eigenvectors and consistent matrixes to create relative weights needed to analyze alternatives or criteria with respect to a decisive judgment in a pairwise comparisons method [29,31]. According to Saaty [29], the AHP assists in dividing the main objective into smaller segments for the purpose of helping decision makers in priority assessment (subjective opinion). To start with, a goal is derived from the stated problem and constructed into a hierarchy structure (from low to high level) with the goal at the top-level. Underneath it, are the criteria, in some cases, sub-criteria as well as the options to be evaluated. However, pairwise comparison allows the analyst to focus on one comparison at a time by comparing among options for each criterion. The pairwise comparisons are transformed to a reciprocal comparison matrix. Inasmuch 
as the matrix is adequately reliable, equation 1 can be used to estimate the priority vector. The priority vector illustrates the relative weights among the criteria and options compared.

$$
A W=\lambda_{\max } W
$$

where $A$ is the comparison matrix, $W$ is the priorities vector, and $\lambda_{\max }$ is the principal eigenvalue.

Since there is redundant or unnecessary information included in the comparison matrix it is necessary for the final result to be synthesis, with the intention of making the procedure less reliant on a single decision. The consistency ratio (CR) is measured (Equation (2)) to confirm the consistency of the judgments and, at the same time, serves as a feedback mechanism:

$$
\begin{gathered}
C R=\frac{C I}{R I} \\
C I=\frac{\lambda_{\max }-n}{n-1}
\end{gathered}
$$

where $C I$ is the consistency index; $n$ is the number of the comparison matrix; and $R I$ is the random consistency index for the $\mathrm{n}^{\text {th }}$ row matrixes of randomly generated pairwise comparisons. i.e. the RI value corresponding to the number of the comparison matrix (or number of criterion) is selected. For instance, if $\mathrm{n}$ is 4 the corresponding RI will be 0.9 and the average RI of 500 (sample size) matrices is illustrated in Table 1 . Saaty highlighted that the CR should be 0.10 or less $(<10 \%)$, otherwise there is a need to remodify the responses (subjective judgments) to reduce the inconsistency. For more studies on AHP, see Saaty [29,31].

Table 1. Random Consistency Index (RI).

\begin{tabular}{cccccccccccccccc}
\hline $\mathbf{n}$ & $\mathbf{1}$ & $\mathbf{2}$ & $\mathbf{3}$ & $\mathbf{4}$ & $\mathbf{5}$ & $\mathbf{6}$ & $\mathbf{7}$ & $\mathbf{8}$ & $\mathbf{9}$ & $\mathbf{1 0}$ & $\mathbf{1 1}$ & $\mathbf{1 2}$ & $\mathbf{1 3}$ & $\mathbf{1 4}$ & $\mathbf{1 5}$ \\
\hline $\mathrm{RI}$ & 0.00 & 0.00 & 0.58 & 0.90 & 1.12 & 1.24 & 1.32 & 1.41 & 1.45 & 1.49 & 1.51 & 1.48 & 1.56 & 1.57 & 1.59 \\
\hline
\end{tabular}

\subsection{Choosing the Utmost Appropriate FBW Treatment Alternative}

A benefit-cost model based on the AHP approach is used to map out and evaluate the treatment option with the intention of conserving the residential environment and enhancing public health by the means of controlling the amount of waste generated, proper sorting, storage, collection, transport, recycling, and disposal [50]. The first step was to break down the structure into further sub objectives in the opposite direction and separate criteria within different hierarchy structures of benefit and cost. The rationale for this breakdown is to group criteria in a similar structure, and it is more comprehensible to compare in this case than in two opposite arrangements. In this aspect, the complete weights can be combined into one hierarchy. Initially, the relative priority of benefits and costs are calculated separately, afterward the overall priority of benefit analysis is divided by the cost analysis to produce the final result.

\subsection{Definitions and Determination of the Goal}

The intention of this empirical inquiry was to identify which FBW treatment technology is the utmost appropriate in handling the waste created in the city of Oita. The most suitable alternative concerning the goal was defined so that multiple, equally significant sub-objectives would be fulfilled. The increase of the combustion efficiency rate through the reduction of the quantity of FBW going to the incinerator thereby leads to a gradual reduction in local air pollution, environmental impact, and increase in renewable energy generation. The second substantial factor is the sustainable FBW treatment leading to integrated management of waste. 


\subsection{Clasification of Criteria and Alternatives into Hierarchy Structure}

Significantly, all the objectives have to be well-defined with the purpose to outline and finalize these criteria. Literature and documents on the area under discussion, including the Food Recycling Act, were consulted. The preliminary criteria selected after carrying out analysis and revision on the Act were then combined with the objectives collected from literature [27,28,40-43,51-53]. In addition, the criteria used are adapted from Babalola's studies [2]. This was done with the purpose of discovering the most comprehensive, functioning, essential, and negligible variety of criteria to characterize diverse objectives [43].

The overall aim is to achieve or to choose the most appropriate FBW treatment facility as well as increasing the standard of FBWM to a sustainable practice. Separating the goal into sub-objectives can lead to finding more goals that can be presented about the current situation in Oita City. To bring this to simplicity, the number of various criteria and goals are structured according to the four main areas of concern, that are environmental, socio-cultural, technical, and economic. These lead to the facilitating and identifying of criteria listed below.

The cost analysis consists of four criteria listed below, which may have direct or indirect mandatory expenditure:
a. Cost of Energy
b. Cost of Operation \& Maintenance
c. Environmental Constraints
d. Disruption/Disturbance/ Disamenity

The benefit criteria consist of those that might attain quantitative or qualitative benefits and four of these criteria were considered:
e. Value Added
f. Safety/Wellbeing/Reliability/Trustworthiness
g. Efficiency/Effectiveness
h. Social Benefits

It is crucial to determine the proper FBW treatment alternatives or options that can accomplish the goals and purposes of the research underline. The set of four alternatives, which was used in the AHP structure is based on the waste disposal type recommended by the Food Waste Recycle Law. The options are mentioned below:
i. Anaerobic Digestion
j. Incineration
k. Compost
1. Landfill

The backbone of the whole AHP approach is a logically structured hierarchy. Figures 2 and 3 show the two separate AHP structures for both benefit and cost analysis. The goals are to select the options with the least cost and the most significant benefits respectively. The first level identifies the goals, and the essential criteria at the second level are comprised of four criteria, whereas the last (third) level contains the options of FBW treatment. Both benefit and cost hierarchies have the same numbers of elements in all levels, except that at the criterion level are different criteria. 


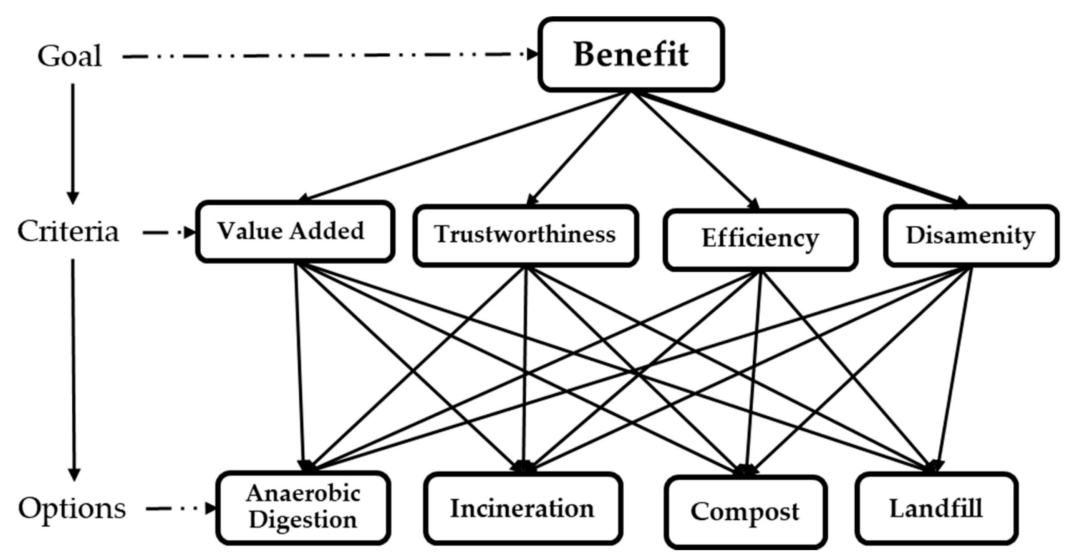

Figure 2. Hierarchy structure for benefit analysis.

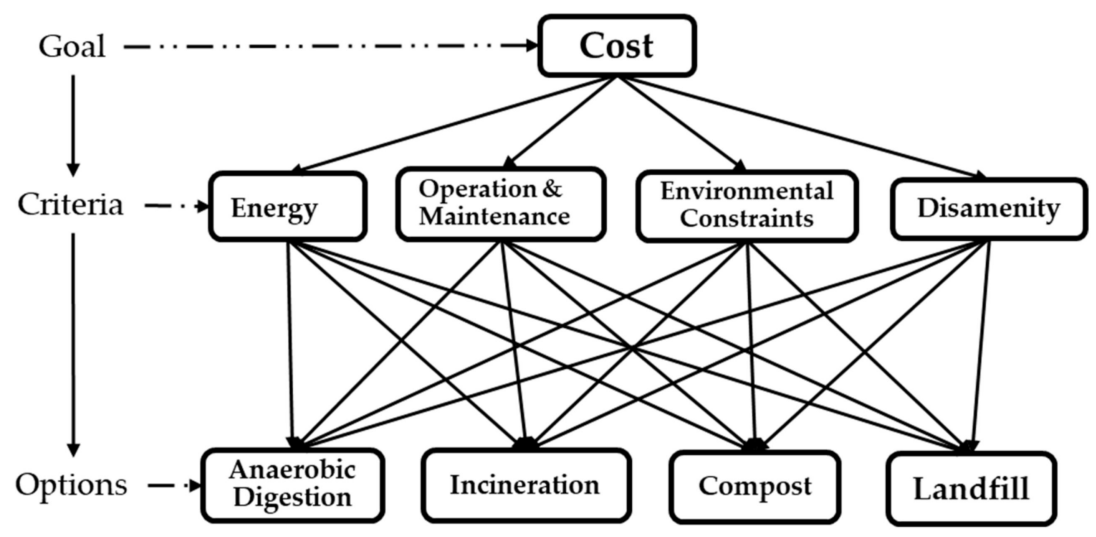

Figure 3. Hierarchy structure for cost analysis.

\section{Results}

\subsection{Pairwise Comparison Matrix (PCM) and Weighting of Criteria}

Fundamentally, there are two methods used when assigning weights or judgment to criteria. They are group opinion (consensus experts/decision-makers) and single opinion (decision-maker/author's judgment) $[29,30,51]$. In theory, no difference in their practical application provided the value of the outcome can be examined by how consistently satisfactory the findings [29]. In each instance, the pairwise comparison judgments are made with each essential factor (in a specified hierarchy structure) in connection with the other component at an equal status. Present study uses the single judgment procedure in conjunction with MSW management regulation and policy in Japan. A separate criterion for both benefit and cost analyses (Figures 2 and 3 ) used in the computing process were split into three key levels. Level one represents the goal, level two is the criteria, while the final standard is the FBW treatment options.

The relative preference of the judgment made for each pairwise comparison is measured in accordance with the 1-9-point scale of preference (Table 2) introduced by Saaty [29,31]. The pairwise comparison of one set of elements at a time is the downside of applying this scale. Comparisons are performed by matching two elements based on the 1-9-point preference scale to indicate how many times more important one factor is over another simultaneously satisfying the reciprocal condition [29,31]. For example, in Table 3, if the Value Added criterion is four times as important (preferable) as the Safety criterion, it implies that Safety is one quarter as preferable as Value Added. 
Table 2. Saaty's pairwise comparison scale.

\begin{tabular}{cc}
\hline Numeric Intensity & Verbal Judgement \\
\hline 9 & Extremely favored \\
8 & Very strongly to extremely \\
7 & Very strongly favored \\
6 & Strongly to very strongly \\
5 & Strongly favored \\
4 & Moderately to strongly \\
3 & Moderately favored \\
2 & Equally to moderately \\
1 & Equally favored \\
\hline
\end{tabular}

Table 3. Pairwise comparison matrix of criteria for benefit.

\begin{tabular}{cccccc}
\hline Criteria/Options & Value Added & Safety & Efficiency & Social Benefits & Priority Vector \\
\hline Value Added & 1 & 4 & 5 & 1 & 0.4101 \\
Safety & $1 / 4$ & 1 & 3 & $1 / 4$ & 0.1390 \\
Efficiency & $1 / 5$ & $1 / 3$ & 1 & $1 / 3$ & 0.0824 \\
Social Benefits & 1 & 4 & 3 & 1 & 0.3685 \\
\hline
\end{tabular}

Note: $\lambda \max =4.2430$, Consistency Index $(C I)=0.0810$, Consistency Ratio $(C R)=0.09<0.1$.

The pairwise comparison matrix consists of a total of five tables, each for the benefit and cost analysis and they are presented in Tables $3-8$ and Tables $10-15$ correspondingly. Table 3 and Table 10 represent the goal criteria, while the remaining denotes the connection of the four alternatives to the "criteria concerned" at all levels. Since all comparisons have less than a $1 \%$ consistency ratio, it is reasonable to conclude that the weights used are reliable and consistent.

Table 4. Pairwise comparison matrix of the alternatives for value added.

\begin{tabular}{cccccc}
\hline Options & Anaerobic Digestion & Incineration & Compost & Landfill & Priority \\
\hline Anaerobic Digestion & 1 & 3 & 7 & 9 & 0.5782 \\
Incineration & $1 / 3$ & 1 & 5 & 7 & 0.2948 \\
Compost & $1 / 7$ & $1 / 5$ & 1 & 2 & 0.0788 \\
Landfill & $1 / 9$ & $1 / 7$ & $1 / 2$ & 1 & 0.0481 \\
\hline
\end{tabular}

Note: $\lambda \max =4.1771, C I=0.0590, C R=0.066<0.1$.

Table 5. Pairwise comparison matrix of the alternatives for safety.

\begin{tabular}{cccccc}
\hline Options & Anaerobic Digestion & Incineration & Compost & Landfill & Priority \\
\hline Anaerobic Digestion & 1 & 3 & $1 / 2$ & 5 & 0.3050 \\
Incineration & $1 / 3$ & 1 & $1 / 4$ & 4 & 0.1490 \\
Compost & 2 & 4 & 1 & 6 & 0.4869 \\
Landfill & $1 / 5$ & $1 / 4$ & $1 / 6$ & 1 & 0.0591 \\
\hline
\end{tabular}

Note: $\lambda \max =4.1856, C I=0.0619, C R=0.069<0.1$.

Table 6. Pairwise comparison matrix of the alternatives for efficiency.

\begin{tabular}{cccccc}
\hline Options & Anaerobic Digestion & Incineration & Compost & Landfill & Priority \\
\hline Anaerobic Digestion & 1 & 3 & 2 & 7 & 0.4656 \\
Incineration & $1 / 3$ & 1 & $1 / 3$ & 5 & 0.1665 \\
Compost & $1 / 2$ & 3 & 1 & 6 & 0.3178 \\
Landfill & $1 / 7$ & $1 / 5$ & $1 / 6$ & 1 & 0.0501 \\
\hline
\end{tabular}

Note: $\lambda \max =4.1827, C I=0.0609, C R=0.068<0.1$. 
Table 7. Pairwise comparison matrix of the alternatives for social benefits.

\begin{tabular}{cccccc}
\hline Options & Anaerobic Digestion & Incineration & Compost & Landfill & Priority \\
\hline Anaerobic Digestion & 1 & 1 & 5 & 7 & 0.4166 \\
Incineration & 1 & 1 & 5 & 7 & 0.4166 \\
Compost & $1 / 5$ & $1 / 5$ & 1 & 4 & 0.1175 \\
Landfill & $1 / 7$ & $1 / 7$ & $1 / 4$ & 1 & 0.0492 \\
\hline
\end{tabular}

Note: $\lambda \max =4.2093, C I=0.0698, C R=0.078<0.1$.

Table 8. Synthesis of all criteria in benefit- composite weight.

\begin{tabular}{cccccc}
\hline Criteria/Options & Value Added & Safety & Efficiency & Social Benefits & Overall Priority \\
\hline Anaerobic Digestion & 0.237 & 0.042 & 0.038 & 0.154 & 0.471 \\
Incineration & 0.121 & 0.021 & 0.014 & 0.154 & 0.309 \\
Compost & 0.032 & 0.068 & 0.026 & 0.043 & 0.170 \\
Landfill & 0.020 & 0.008 & 0.004 & 0.018 & 0.050 \\
\hline
\end{tabular}

\subsection{Benefit Analysis}

The particular aim of benefit analysis is to evaluate which waste treatment options would be the most beneficial to treat the amount of FBW generated. As well as the possibilities of increasing the efficiency rate, social benefits, and better resource recovery. The options on the left are objectively paired with the options on top in terms of value added, safety, efficiency, and social benefits in Tables $4-7$, respectively.

Overall consistency of the hierarchy:

Çî́ $=\frac{\sum_{\mathrm{i}} \mathrm{Wi} \mathrm{Cli}}{\sum_{\mathrm{i}} \mathrm{Wi}_{\mathrm{Rli}}}=\frac{0.1445}{1.8000}=0.080<0.1$

The options on the left are objectively paired with the options on top in terms of value added, safety, efficiency, and social benefits in Tables $4-7$ respectively. Each matrix priority was obtained from the comparisons matrix and presented in Table 8 and the standings of the choices are compared against the four criteria concerned. The entire matrix shown in Table 8. The result shown in Table 9 reports the idealized and normalized priorities. The idealized priority is obtained by dividing each priority by the largest value. So as to make the largest priority ideal alternative and while the others receive their proportionate value (same procedure is applied in the cost analysis). Subsequently, the result implies that anaerobic digestion has the highest benefit with 0.47 of its normalized priority, while incineration is about $65 \%$ of the benefit of anaerobic digestion, and so on.

Table 9. Normalized and idealized priorities.

\begin{tabular}{ccc}
\hline Criteria/Options & Normalized Priorities & Idealized Priorities \\
\hline Anaerobic Digestion & 0.4714 & 1.0000 \\
Incineration & 0.3088 & 0.6551 \\
Compost & 0.1695 & 0.3596 \\
Landfill & 0.0502 & 0.1065 \\
\hline
\end{tabular}

\subsection{Cost Analysis}

The specific objective of the cost analysis is to examine which waste treatment alternatives would be the least costly to treat the amount of FBW generated, along with the outcomes of reduction in air pollution, maintenance, and operating costs, renewable energy generation, ecological impact, and disamenity. The options on the left are paired with the options on top in terms of the cost of energy, operation, and maintenance, environmental constraints, and disruption/disturbance/disamenity in Tables 10-14 respectively. 
Table 10. Pairwise comparison matrix of Criteria for cost.

\begin{tabular}{cccccc}
\hline Criteria & Energy & O\&M & En Constraints & Disamenity & Priority \\
\hline Energy & 1 & 2. & 2 & 2 & 0.3830 \\
O\&M & $1 / 2$ & 1 & $1 / 4$ & $1 / 3$ & 0.1089 \\
En Constraints & $1 / 2$ & 4 & 1 & 1 & 0.2665 \\
Disamenity & $1 / 2$ & 3 & 1 & 1 & 0.2415 \\
\hline
\end{tabular}

Note: $\lambda \max =4.2262, C I=0.0754, C R=0.067<0.1$.

Table 11. Pairwise comparison matrix of the alternatives for energy.

\begin{tabular}{cccccc}
\hline Options & Anaerobic Digestion & Incineration & Compost & Landfill & Priority \\
\hline Anaerobic Digestion & 1 & $1 / 7$ & $1 / 2$ & $1 / 3$ & 0.0663 \\
Incineration & 7 & 1 & 7 & 7 & 0.6813 \\
Compost & 2 & $1 / 7$ & 1 & 1 & 0.1166 \\
Landfill & 3 & $1 / 7$ & 1 & 1 & 0.1358 \\
\hline
\end{tabular}

Note: $\lambda \max =4.2102, C I=0.0701, C R=0.078<0.1$.

Table 12. Pairwise comparison matrix of the alternatives for operation and maintenance.

\begin{tabular}{cccccc}
\hline Options & Anaerobic Digestion & Incineration & Compost & Landfill & Priority \\
\hline Anaerobic Digestion & 1 & $1 / 3$ & 2 & $1 / 3$ & 0.1348 \\
Incineration & 3 & 1 & 5 & 3 & 0.4955 \\
Compost & $1 / 2$ & $1 / 5$ & 1 & $1 / 5$ & 0.0737 \\
Landfill & 3 & $1 / 3$ & 5 & 1 & 0.2959 \\
\hline
\end{tabular}

Note: $\lambda \max =4.2360, C I=0.0787, C R=0.087<0.1$.

Table 13. Pairwise comparison matrix of the alternatives for environmental constraints.

\begin{tabular}{cccccc}
\hline Options & Anaerobic Digestion & Incineration & Compost & Landfill & Priority \\
\hline Anaerobic Digestion & 1 & $1 / 5$ & 2 & $1 / 9$ & 0.0723 \\
Incineration & 5 & 1 & 8 & $1 / 9$ & 0.3284 \\
Compost & $1 / 2$ & $1 / 8$ & 1 & $1 / 9$ & 0.0461 \\
Landfill & 9 & 2 & 9 & 1 & 0.5532 \\
\hline
\end{tabular}

Note: $\lambda \max =4.0871, C I=0.0290, C R=0.032<0.1$.

Table 14. Pairwise comparison matrix of the alternatives for disamenity.

\begin{tabular}{cccccc}
\hline Options & Anaerobic Digestion & Incineration & Compost & Landfill & Priority \\
\hline Anaerobic Digestion & 1 & $1 / 2$ & 3 & $1 / 5$ & 0.1287 \\
Incineration & 2 & 1 & 5 & $1 / 3$ & 0.2333 \\
Compost & $1 / 3$ & $1 / 5$ & 1 & $1 / 9$ & 0.0514 \\
Landfill & 5 & 3 & 9 & 1 & 0.5866 \\
\hline
\end{tabular}

Note: $\lambda \max =4.0590, C I=0.0197, C R=0.022<0.1$.

Overall consistency of the cost hierarchy:

$$
\text { Ḉি }=\frac{\sum_{\mathrm{i}} \mathrm{Wi} \mathrm{Cli}}{\sum_{\mathrm{i}} \mathrm{Wi} \text { RIi }}=\frac{0.1233}{1.8000}=0.068<0.1
$$

Each matrix priority was obtained from the comparison matrix and presented in Table 14. The classifications of the alternatives were compared against the four criteria concerned. All matrixes are in synthesis in Table 15. The result in Table 16 shows the idealized and normalized score. Subsequently, 
the result implies that compost cost the least with 0.077 of its normalized priority, while anaerobic digestion costs about $9 \%$ less than compost, and so on.

Table 15. Synthesis for all criteria in cost - composite weight.

\begin{tabular}{cccccc}
\hline Criteria/Options & Energy & Operation & En Constraints & Disamenity & Overall Priority \\
\hline Anaerobic Digestion & 0.025 & 0.015 & 0.019 & 0.031 & 0.090 \\
Incineration & 0.261 & 0.054 & 0.088 & 0.056 & 0.459 \\
Compost & 0.045 & 0.008 & 0.012 & 0.012 & 0.077 \\
Landfill & 0.052 & 0.032 & 0.147 & 0.142 & 0.373 \\
\hline
\end{tabular}

Table 16. Normalized and idealized priorities.

\begin{tabular}{ccc}
\hline Criteria/Options & Normalized Priorities & Idealized Priorities \\
\hline Anaerobic Digestion & 0.0904 & 0.1971 \\
Incineration & 0.4588 & 1.0000 \\
Compost & 0.0774 & 0.1686 \\
Landfill & 0.3734 & 0.8137 \\
\hline
\end{tabular}

\subsection{Benefit Cost Analysis}

From Table 8, one can conclude that the least cost alternative is composting, given that it scored the least, in addition, the alterative with the highest benefit priority is anaerobic digestion in the case of benefit analysis (Table 15). There is comparability in this instance, as the benefit and cost analysis lead toward different rankings [45]. Consequently, it is proper to carry out the benefit-cost ratio analysis to determine the final ranking based on the most suitable option in accordance with the outcomes of the benefit and cost examination. Therefore, judging from the result in Table 17, the benefit-cost ratio implies that anaerobic digestion remains a suitable alternative.

Table 17. Benefit cost analysis.

\begin{tabular}{cccc}
\hline Criteria/Options & Cost & Benefit & Benefit/Cost \\
\hline Anaerobic Digestion & 0.0904 & 0.4714 & 5.2132 \\
Incineration & 0.4588 & 0.3088 & 0.6731 \\
Compost & 0.0774 & 0.1695 & 2.1907 \\
Landfill & 0.3734 & 0.0502 & 0.1345 \\
\hline
\end{tabular}

\subsection{Sensitivity Test}

Sensitivity examination constitutes an integral part and standard procedure in MCDA to determine the soundness of the binding decision made and in what manner these diverse priority preferences influenced the judgments [28,39,52]. Thus, it explains the possibility of various informed decisions made by the decision-makers pertaining to the criteria adopted and how they exert influence on the judgment outcomes.

The examination was performed by modifying the priority weights of each criterion one at a time in a separate analysis of both benefit and cost and by compiling the account of the variations in the rank outcomes. The possible scenarios used for benefit and cost analyses are illustrated below:

(a) The first scenario illustrated how three out of four criteria are assigned with zero (0) priority weights while the remaining criterion was allocated with one in a composition of four potential chances. The benefit scenario is given in Figure 4a, while that of the cost is in Figure 5a, which ranked anaerobic digestion as optimal performing alternative in two of the criteria (value added and efficiency), and composting ranked top in safety criterion. Whereas both anaerobic digestion and composting maintained the same performance, in the case of cost analysis, incineration and land fill scored as the most cost effective alternatives in terms of energy, operation, and disamenity criteria, while composting and anaerobic digestion were the least cost efficient alternatives. 
(b) The priority weights of 0.5 were assigned to two out of four criteria and zero (0) to the other in the second scenario (together with benefit and cost analysis) in a combination of six potential chances (similar results). Only one out of six possibilities are shown in Figures $4 \mathrm{~b}$ and $5 \mathrm{~b}$, and the outcome is comparable to the outcome in the first scenario.
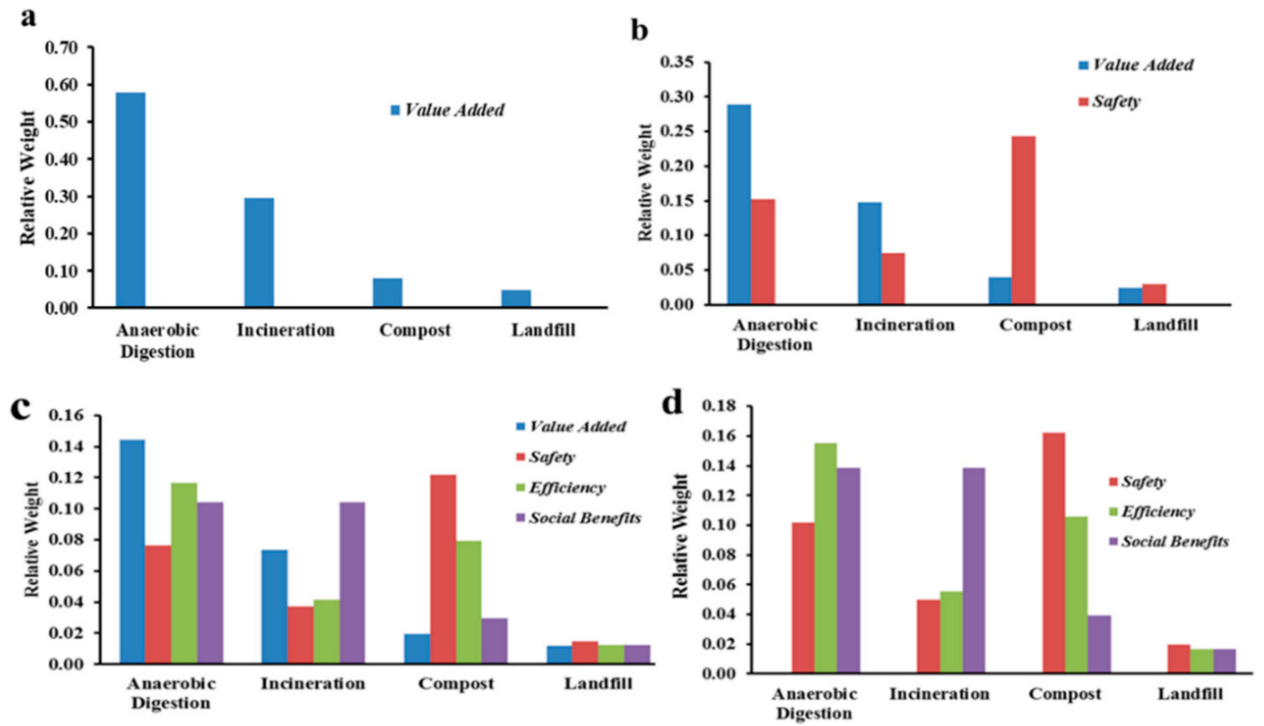

Figure 4. Sensitivity analysis: (a) only one criterion is assigned to the priority weight of one; (b) two criteria are allocated with 0.5 ; (c) all criteria have the same priority weight of 0.25 ; (d) three criteria are assigned to 0.33 .

(c) The third scenario is the combination of only one possibility with all four criteria having equal priority weights of 0.25 each, for benefit and cost analysis (Figures $4 c$ and $5 c$ ). The investigation presents an increasingly evident outcome similarly to the first scenario. Subsequently, the performance of anaerobic digestion and composting outweighs other alternatives in all the criteria both in the benefit and cost analysis. Consequently, it is proper to correctly deduce that anaerobic digestion is the utmost choice for proper FBW handling accompanied by compost as well as incineration, whereas landfill remains the worst [2].

(d) In the last scenario, three out of four of the criteria were assigned to the priority weight of 0.33 each, and zero (0) to the fourth criterion in a combination of four potential chances. Only one of the four possibilities (for benefit and cost analysis) is presented in Figures $4 \mathrm{~d}$ and $5 \mathrm{~d}$, and the result shows a similar outcome to that of the third scenario.

The sensitiveness across all four scenarios shows similar outcomes, which can be inferred from Figures 4 and 5. Anaerobic digestion is seen to outperform other alternatives as to the most suitable choice for FBWM, followed by composting, which also had a more satisfactory performance in some of the criteria, and incineration. The last to be considered is landfill. 

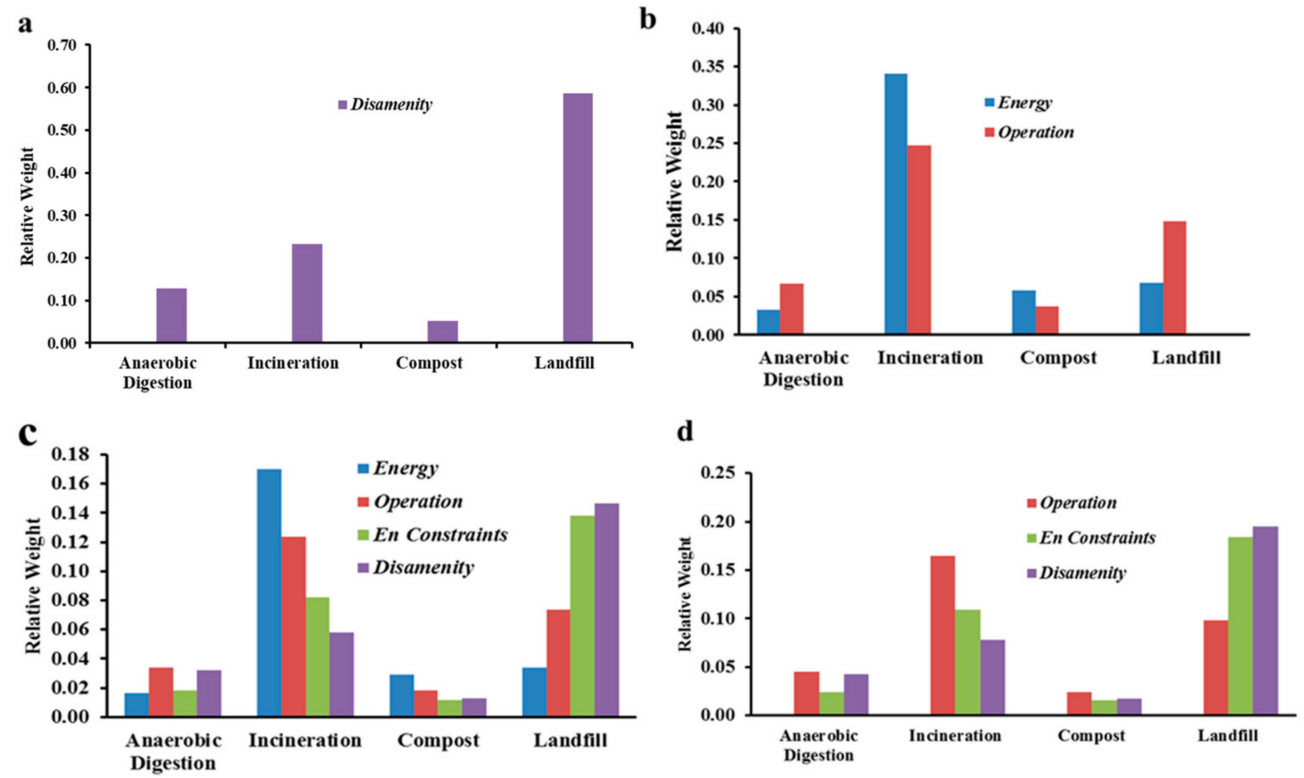

Figure 5. Sensitivity analysis: (a) only one criterion is assigned to the priority weight of one; (b) two criteria are allocated with 0.5 ; (c) all criteria have the same priority weight of 0.25 ; (d) three criteria are assigned to 0.33 .

\section{Discussion}

In this study, benefit-cost analysis based on AHP model was the MCDA approach used to examine and assess the FBW treatment alternatives. The standard AHP model integrates a significant amount of pairwise comparisons amidst criteria, sub-criteria, and between choices within a dependable set of scaled weights, which facilitates choosing the appropriate decision. The model hierarchy in this study was separated into two parts of the analysis (benefit and cost) with each set of judgments, having one goal, four criteria, and four alternatives structured within three stages. The criteria comprised the main concerns involved in waste management, for instance, environmental, socio-cultural, technical, and economic aspects, leading to the development of the AHP based benefit-cost model. This model was utilized to assess and estimate the performance of each option and the result turned out to be in favor of anaerobic digestion. The analysis was done on a comparison scale, which meant the cost analysis against the benefit analysis.

However, the result shows that incineration and landfill hold respectively the highest cost priority weights of 0.4588 and 0.3734 . Anaerobic digestion and compost hold a share lower priority value of 0.0904 and 0.0774 . In the cost analysis, the cost of energy had the most significant relative weight of 0.3830among all the cost criteria. The environmental constraints and disamenity follow with their relative weight of 0.2665 and 0.2415 , respectively, while operation and maintenance possess the most reduced relative weight of 0.1089 .

Benefit analysis illustrates that anaerobic digestion is the most beneficial, with the relative weight of 0.4714. Incineration and compost are next with their resulting priority weights of 0.3088 and 0.1695 . Value added had the highest priority weight of 0.4101 in the goal category and followed social benefits with the priority weight of 0.3685 . While the system's efficiency and safety had theirs to be 0.824 and 0.1390. After the priority value of benefit and cost are separately analyzed, the adjusted priority weight of the benefit analysis was then divided by that of the cost analysis to produce the result. As such, the total standardized benefit-cost ratio was obtained for respective alternatives.

As a result, anaerobic digestion became the most uppermost benefit-cost ratio, with a priority weight of 5.2132. Compost had the next most relative weight of 2.1907. The worst options with the lowest benefit to cost ratios were incineration and landfill, respectively holding weights of 0.6731 and 0.1345 . The sensitivity analysis performed on both benefit and cost resulted in using four different 
scenarios to see if there would be any change in the performance of the final result among all alternatives. The result showed a similar case as the synthesis result (final result), making anaerobic digestion the most suitable treatment alternative. Thus, it is demonstrated that the judgment of the treatment alternatives based on the criteria used for benefit and cost analyses was a robust one. The findings are comparable to the analysis carried out by Babalola [2] in a similar study.

However, incineration alone cannot achieve such sufficiency of using MSW as renewable resources. Similarly, there are numerous ecological benefits of treating FBW in anaerobic digestion. Same observation was made by Abba et al. [51] and Hanan et al. [52] in their application of the MCDA approach in selecting waste treatment alternatives based on their environmental impacts. In addition to these benefits is a decrease in the cost of treatment, an increase in combustion efficiency, as well as the value of recyclable materials and the reduction of the number of wet FBW substances. For this reason, it would be of a significant benefit if FBW were properly treated or disposed of in a more dependable treatment facility other than incineration $[7,11,17,54,55]$.

Usually, stakeholder participatory or panel of experts are included in MCDA as part of the decision-making group that allocates weights and scores. It is extremely important to spell out that the weights used in this study were not based on monetary value, rather on the subjective judgments of the author founded on the standard of the Food Recycling Act in Japan and related literature. The subjective approach of this study is relevant to the application of AHP since only specific issues were being addressed. Therefore, the proposed framework does not require a large number of opinion experts in order to analyze the result. On the other hand, a higher degree of inconsistency is generally related to a large number of experts, as judgments made based on a diverse set of criteria would produce diverse results. Consequently, this study could be acknowledged as an adaptable framework that can be improved upon to fit in more criteria and options. In addition, it could provide an opportunity for more panels of experts or stakeholders to be involved in the decision-making process.

The AHP benefit-cost analysis demonstrated in this research signifies the operational effectiveness and practicality of its application in meaningfully addressing waste management concerns. Furthermore, it presents a significant understanding of the waste management objectives of Oita City, Japan.

\section{Conclusions}

The practical application of MCDA has emerged in the decision-making process as one essential instrument towards evaluating performance, choice of options, benefit-cost analysis, site selection, and making comparisons across plants, policies, private sectors, or time periods. AHP for evaluating performance, selection of options, benefit-cost analysis and site selection have become indispensable policy tools for decision makers. As the AHP benefit-cost analysis becomes more commonly applied in a variety of situations, MCDA approaches follow some key guidelines to make them fair and meaningful.

This study showed clearly a comparative assessment of the current FBW treatment option in Oita City, in line with the Food Waste Recycling Act. The investigation is in accordance with MSW practices (waste collection and disposal), the amount of generated waste, reuse, recycling, and reduction. Thus, the proposed solution could be seen as an enhancement upon the current practice and existing system of FBW management.

The outcomes implied the best and the most suitable alternatives aimed at handling the FBW was anaerobic digestion and followed by composting. Incineration became the third most suitable alternative in terms of the overall result, while landfill was assumed mostly as the worst-case because of the significant costs and low benefits.

The conceptual model illustrated in this study has the possibility to be employed as a systematic strategic decision supporting instrument. Capable of providing decision-makers with significant and dependable information on the assessment procedure of selecting the most appropriate disposal technology for FBW in accordance with economic, social, cultural, technical, and ecological concerns. 
Subsequent research would be to apply the proposed framework in a factual situation using a committee of specialists and non-experts as well as monetized criteria where necessary (in cost analysis). Correspondingly, the committee of experts are allowed to explore different necessary conditions, parameters, and options of waste treatment from the ones analyzed in this paper.

Author Contributions: The author is the lead for all aspects of this research.

Funding: This research received no external funding.

Conflicts of Interest: The authors declare no conflict of interest.

\section{References}

1. United Nations. Transforming Our World: The 2030 Agenda for Sustainable Development; United Nations Publication: New York, NY, USA, 2015.

2. Babalola, M.A. A multi-criteria decision analysis of waste treatment options for food and biodegradable waste management in Japan. Environments 2015, 2, 471-488. [CrossRef]

3. Okuda, I.; Thomson, V.E. Regionalization of municipal solid waste management in Japan: Balancing the proximity principle with economic efficiency. Environ. Manag. 2007, 40, 12-19. [CrossRef] [PubMed]

4. Sakai, S.; Sawell, S.E.; Chandler, A.J.; Eighmy, T.T.; Kosson, D.S.; Vehlow, J.; Van der Sloot, H.A.; Hartlen, J.; Hjelmar, O. World trends in municipal solid waste management. Waste Manag. 1996, 16, 341-350. [CrossRef]

5. Takata, M.; Fukushima, K.; Kino-Kimata, N.; Nagao, N.; Niwa, C.; Toda, T. The effects of recycling loops in food waste management in Japan: Based on the environmental and economic evaluation of food recycling. Sci. Total Environ. 2012, 432, 309-317. [CrossRef]

6. Ministry of the Environment (MOE). Establishing a Sound Material-Cycle Society: Milestone toward a Sound Material-Cycle Society through Changes in Business and Life Styles; Ministry of the Environment Government: Tokyo, Japan, 2010.

7. Wong, L.-F.; Fujita, T.; Xu, K. Evaluation of regional bioenergy recovery by local methane fermentation thermal recycling systems. Waste Manag. 2008, 28, 2259-2270. [CrossRef]

8. Yolin, C. Waste Management and Recycling in Japan Opportunities for European Companies (SMEs Focus); EU-Japan Centre for Industrial Cooperation: Tokyo, Japan, 2015.

9. Oita Municipal Government. Oita Zero Waste Strategy: The Status and Plans of Biomass Resource Utilization; Oita Municipal Government: Oita City, Japan, 2014.

10. Oita City. Statistics of Oita-City (2017 version). 2018. Available online: http://www.city.oita.oita.jp.e.adk.hp. transer.com/o001/shisejoho/annai/tokei-nenkan-h29.html (accessed on 22 April 2018).

11. Babalola, M.A. A system dynamics-based approach to help understand the role of food and biodegradable waste management in respect of municipal waste management systems. Sustainability 2019, 11, 3456. [CrossRef]

12. Oita Pride. Oita City Outline 2017. Available online: http://www.city.oita.oita.jp/o029/shisejoho/annai/ documents/english.pdf (accessed on 22 April 2018).

13. Geng, Y.; Tsuyoshi, F.; Chen, X. Evaluation of innovative municipal solid waste management through urban symbiosis: A case study of Kawasaki. J. Clean. Prod. 2010, 18, 993-1000. [CrossRef]

14. Caruso, M.C.; Braghieri, A.; Capece, A.; Napolitano, F.; Romano, P.; Galgano, F.; Altieri, G.; Genovese, F. Recent Updates on the Use of Agro-Food Waste for Biogas Production. Appl. Sci. 2019, 9, 1217. [CrossRef]

15. Tabata, T. Waste-to-energy incineration plants as greenhouse gas reducers: A case study of seven Japanese metropolises. Waste Manag. Res. 2013, 31, 1110-1117. [CrossRef]

16. Bernstad, A.; la Cour Jansen, J. Review of comparative LCAs of food waste management systems-Current status and potential improvements. Waste Manag. 2012, 32, 2439-2455. [CrossRef]

17. ISWA-The International Solid Waste Association. Food Waste as a Global Issue-From the Perspective of Municipal Solid Waste Management; ISWA Publications: Vienna, Austria, 2013.

18. Khalid, A.; Arshad, M.; Anjum, M.; Mahmood, T.; Dawson, L. The anaerobic digestion of solid organic waste. Waste Manag. 2011, 31, 1737-1744. [CrossRef] [PubMed]

19. Khoo, H.H.; Lim, T.Z.; Tan, R.B.H. Food waste conversion options in Singapore: Environmental impacts based on an LCA perspective. Sci. Total Environ. 2010, 408, 1367-1373. [CrossRef] [PubMed] 
20. Kim, M.-H.; Kim, J.-W. Comparison through an LCA evaluation analysis of food waste disposal options from the perspective of global warming and resource recovery. Sci. Total Environ. 2010, 408, 3998-4006. [CrossRef] [PubMed]

21. Villanueva, A.; Wenzel, H. Paper waste-Recycling, incineration or landfilling? A review of existing life cycle assessments. Life Cycle Assessment in Waste Management. Waste Manag. 2007, 27, 29-46. [CrossRef]

22. Santibañez-Aguilar, J.E.; Ponce-Ortega, J.M.; Betzabe González-Campos, J.; Serna-González, M.; El-Halwagi, M.M. Optimal planning for the sustainable utilization of municipal solid waste. Waste Manag. 2013, 33, 2607-2622. [CrossRef]

23. Cotana, F.; Vittori, F.; Marseglia, G.; Medaglia, C.M.; Coccia, V.; Petrozzi, A.; Nicolini, A.; Cavalaglio, G. Pollutant emissions of a biomass gasifier inside a multifuel energy plant. Atmos. Pollut. Res. 2019, 10, 2000-2009. [CrossRef]

24. Marseglia, G.; Medaglia, C.M.; Petrozzi, A.; Nicolini, A.; Cotana, F.; Sormani, F. Experimental tests and modeling on a CHP biomass plant. Energies 2019, 12, 2615. [CrossRef]

25. Ministry of Agriculture, Forestry and Fisheries (MAFF). Annual Report on Food, Agriculture and Rural Areas in Japan FY, Ministry of Agriculture, Forestry and Fisheries. 2007. Available online: http://www.maff. go.jp/e/annual_report/2007/pdf/e_all.pdf (accessed on 20 September 2015).

26. Al-Harbi, K.M.A.-S. Application of the AHP in project management. Int. J. Proj. Manag. 2001, 19, $19-27$. [CrossRef]

27. Garfi, M.; Tondelli, S.; Bonoli, A. Multi-criteria decision analysis for waste management in Saharawi refugee camps. Waste Manag. 2009, 29, 2729-2739. [CrossRef]

28. Karagiannidis, A.; Papageorgiou, A.; Perkoulidis, G.; Sanida, G.; Samaras, P. A multi-criteria assessment of scenarios on thermal processing of infectious hospital wastes: A case study for Central Macedonia. Waste Manag. 2010, 30, 251-262. [CrossRef]

29. Saaty, T.L. The Analytic Hierarchy Process: Planning, Priority Setting, Resource Allocation; McGraw-Hill: New York, NY, USA, 1980.

30. Saaty, T.L.; Sagir, M. An essay on rank preservation and reversal. Math. Comp. Model. 2009, 49, 1230-1243. [CrossRef]

31. Saaty, T.L.; Vargas, L.G. Models, Methods, Concepts \& Applications of the Analytic Hierarchy Process; Kluwer Academic Publishers: Boston, MA, USA, 2001.

32. Vaidya, O.S.; Kumar, S. Analytic hierarchy process: An overview of applications. Eur. J. Oper. Res. 2006, 169, 1-29. [CrossRef]

33. Anagnostopoulos, K.P.; Petalas, C. A fuzzy multicriteria benefit-cost approach for irrigation projects evaluation. Agric. Water Manag. 2011, 98, 1409-1416. [CrossRef]

34. Belton, V.; Steward, T. Multiple Criteria Decision Analysis: An. Integrated Approach; Springer US: New York, NY, USA, 2002.

35. Dodgson, J.S.; Spackman, M.; Pearman, A.; Phillips, L.D. Multi-Criteria Analysis: A Manual. Available online: http://eprints.lse.ac.uk/12761/ (accessed on 25 September 2015).

36. Nijkamp, P.; Rietveld, P.; Voogd, H. Multicriteria Evaluation in Physical Planning; Elsevier Science Publishing: Amsterdam, The Netherlands, 1990.

37. Herath, G.; Prato, T. Role of multi-criteria decision making in natural resource management. In Using Multi-Criteria Decision Analysis in Natural Resource Management; Herath, G., Prato, T., Eds.; Ashgate Publishing Ltd.: London, UK, 2006.

38. Yeh, C.-H.; Willis, J.R.; Deng, H.; Pan, H. Task oriented weighting in multi-criteria analysis. Eur. J. Oper. Res. 1999, 119, 130-146. [CrossRef]

39. Khalili, N.R.; Duecker, S. Application of multi-criteria decision analysis in design of sustainable environmental management system framework. J. Clean Prod. 2013, 47, 188-198. [CrossRef]

40. Chung, S.S.; Poon, C.S. Evaluating waste management alternatives by the multiple criteria approach. Resour. Conserv. Recycl. 1996, 17, 189-210. [CrossRef]

41. De Feo, G.; de Gisi, S. Using an innovative criterion weighting tool for stakeholder's involvement to rank MSW facility sites with the AHP. Waste Manag. 2010, 30, 2370-2382. [CrossRef]

42. Generowicz, A.; Kulczycka, J.; Kowalski, Z.; Banach, M. Assessment of waste management technology using BATNEEC options, technology quality method and multi-criteria analysis. J. Environ. Manag. 2011, 92, 1314-1320. [CrossRef] 
43. Hokkanen, J.; Salminen, P. Choosing a solid waste management system using multicriteria decision analysis. Eur. J. Oper. Res. 1997, 98, 19-36. [CrossRef]

44. William, H. Integrated analytic hierarchy process and its applications-A literature review. Eur. J. Oper. Res. 2008, 186, 211-228.

45. Ishizaka, A.; Labib, A. Review of the main developments in the analytic hierarchy process. Expert Syst. Appl. 2011, 38, 14336-14345. [CrossRef]

46. Beria, P.; Maltese, I.; Mariotti, I. Multicriteria versus cost benefit analysis: A comparative perspective in the assessment of sustainable mobility. Eur. Transp. Res. Rev. 2012, 4, 137-152. [CrossRef]

47. Wedley, W.C.; Choo, E.U.; Schoner, B. Magnitude adjustment for AHP benefit/cost ratios. Eur. J. Oper. Res. 2001, 133, 342-351. [CrossRef]

48. Wedley, W.C.; Choo, E.U.; Wijnmalen, D.J.D. Benefit/cost priorities-Achieving commensurability. Proc. ASAC 2003, 24, 85-94.

49. Huang, I.; Keisler, J.; Linkov, I. Multi-criteria decision analysis in environmental sciences: Ten years of applications and trends. Sci. Total Environ. 2011, 19, 3578-3594. [CrossRef]

50. Ministry of the Environment. Regulations of Waste Management and Public Cleansing Law. Available online: https://www.env.go.jp/en/laws/recycle/03.pdf (accessed on 20 September 2015).

51. Abba, A.H.; Noor, Z.Z.; Yusuf, R.O.; Din, M.F.M.D.; Hassan, M.A.A. Assessing environmental impacts of municipal solid waste of Johor by analytical hierarchy process. Resour. Conserv. Recycl. 2013, 73, 188-196. [CrossRef]

52. Hanan, D.; Burnley, S.; Cooke, D. A multi-criteria decision analysis assessment of waste paper management options. Waste Manag. 2013, 33, 566-573. [CrossRef]

53. Korucu, M.K.; Erdagi, B. A criticism of applications with multi-criteria decision analysis that are used for the site selection for the disposal of municipal solid wastes. Waste Manag. 2012, 32, 2315-2323. [CrossRef]

54. Franchetti, M. Economic and environmental analysis of four different configurations of anaerobic digestion for food waste to energy conversion using LCA for: A food service provider case study. J. Environ. Manag. 2013, 123, 42-48. [CrossRef]

55. The Ministry of Environment (MOE). Solid Waste Management and Recycling Technology of Japan: Toward a Sustainable Society; The Ministry of Environment (MOE): Tokyo, Japan, 2012.

(C) 2020 by the author. Licensee MDPI, Basel, Switzerland. This article is an open access article distributed under the terms and conditions of the Creative Commons Attribution (CC BY) license (http://creativecommons.org/licenses/by/4.0/). 